\title{
Cartas sobre la primera edición de Salamandra (1962) en Joaquín Mortiz
}

\author{
Aurora Díez-Canedo F. \\ Universidad Nacional Autónoma de México \\ a.diezcanedof@gmail.com
}

\begin{abstract}
Resumen: En el archivo de Joaquín Díez-Canedo M. se conserva parte de su correspondencia con Octavio Paz, gracias a lo cual es posible conocer hoy la expectativa y pormenores de la edición de Salamandra. Junto con el libro de Luis Cernuda, Desolación de la quimera, fueron éstos los dos primeros títulos de la colección de poesía Las Dos Orillas, de la recién fundada editorial Joaquín Mortiz. La presente selección es testimonio del trato que tuvieron en esos años el poeta mexicano y su editor, y permite acercarse al mundo de la edición en los años sesenta, no sólo en México.
\end{abstract}

Palabras Clave: Joaquín Mortiz; Octavio Paz; Salamandra; Desolación de la quimera; André Breton; correspondencias.

Aвstract: Among Joaquín Díez-Canedo M.'s papers, is kept a part of his correspondence with Octavio Paz, which today enables us to know the expectations and details of Salamandra's editing process. Together with Luis Cernuda's book, Desolación de la quimera, these were the first two volumes of Las Dos Orillas, the poetry collection within the newly found editorial Joaquín Mortiz. The letters here included are a testimony of the relationship in those years between the Mexican poet and his publisher, and allow us to get close to publishing in the decade of 1960, not only in Mexico.

Keywords: Joaquín Mortiz; Octavio Paz; Salamandra; Desolación de la quimera; André Breton; correspondences.

FeCha DE RECEPCIÓN: 21 de marzo de 2016.

FECHA DE ACEPTACión: 8 de mayo de 2016.

París, probablemente octubre de i96 I

Tras dejar el Fondo de Cultura Económica a fines de agosto, Joaquín

1 Díez-Canedo, que no entra a España mientras vive Franco, hace un viaje a la capital francesa para entrevistarse allá con Víctor Seix y Carlos 
Barral, que serán sus socios españoles en la editorial que acaba de fundar con el nombre de Joaquín Mortiz.

Se reúne también con Octavio Paz, que vive en París desde 1958 y se desempeña como Encargado de negocios ad interim de la embajada de México hasta $1961 .{ }^{1}$ Acuerdan la publicación del libro de poemas en que Paz se encuentra trabajando, titulado La salamandra y concretan dos proyectos: la traducción de los poemas de A. O. Barnabooth de Valery Larbaud, y la edición de las novelas de André Breton. Si bien el primer proyecto no llegó a realizarse, la idea de Paz de publicar en México a Breton en un solo volumen con un prólogo suyo tuvo como resultado la edición de tres títulos de Breton en la Serie del Volador, colección de libros de bolsillo de Joaquín Mortiz: Nadja (1963), Los vasos comunicantes (1965) y El amor loco (1967).

A través de los contactos que establecen, se vinculan con el mundo de la edición francesa de principios de los sesenta. Uno de los protagonistas de este momento, el editor Jean-Jacques Pauvert (n. 1926), escribe en sus memorias: "La edición consiste fundamentalmente en encuentros" (200). Esta frase del editor de las obras completas del marqués de Sade, de Malraux, Gide, Quenau, Boris Vian, Bataille, entre otros, quien a la sazón tiene los derechos de traducción de André Breton, resulta útil como punto de partida para tratar acerca de los proyectos de edición moldeados entre Paz y Díez-Canedo en París, que entre otros temas son tratados en la presente selección de cartas.

El poeta y el editor se conocían de tiempo atrás, pues Paz había publicado en el Fondo de Cultura Económica libros como Libertad bajo palabra (Tezontle, 1949) y El arco y la lira (1956), pero ahora la situación era distinta. Gracias a una carta de Cernuda, y a las noticias que le da Carlos Fuentes a su paso por París, Paz está al tanto de los planes de Díez-Canedo de establecer una editorial propia enfocada a la literatura. ${ }^{2}$

Salamandra, ya sin el artículo, y Desolación de la quimera de Luis Cernuda, serán los dos primeros títulos de la colección de poesía de la editorial Joaquín Mortiz, titulada Las Dos Orillas. Es un comienzo excelente para poner en marcha la idea que tenía Díez-Canedo de "juntar

1 Manual de organización de la Embajada de México en Francia (11) <www.sre. gob.mx>.

${ }^{2}$ La empresa queda registrada con el nombre de Editorial Joaquín Mortiz, S.A. de C.V. 
lo mejor del exilio español con lo mejor de la poesía mexicana” en su editorial (Ulacia: 88).

La relación entre estos dos escritores tiene su historia y para ilustrarla incluyo la siguiente anécdota. Cuando en septiembre de 1958, el Fondo de Cultura Económica publicó La realidad y el deseo de Cernuda, el poeta sevillano que había conocido a Paz durante la Guerra Civil española ${ }^{3}$ y entonces residía en México como exiliado, invitó a cenar a Díez-Canedo, Alí Chumacero (que se habían encargado del proceso de edición de su libro) y a Octavio Paz. De este último, Cernuda escribe a Bernabé Fernández-Canivell ${ }^{4}$ en España: "es un poeta de valor y a cuyos elogios debo sin duda la decisión de editar este libro" (Valender: 709).

Más que referirse en detalle a la edición de Salamandra, las cartas seleccionadas aquí interesan como testimonio de una época y de momentos de transición y cambio en la vida y trayectoria de cada uno de los interlocutores: por un lado, los planes y problemas que enfrenta Joaquín DíezCanedo en los primeros meses de vida de su nueva editorial Joaquín Mortiz, llamada a ocupar un lugar importante en la vida cultural mexicana de por lo menos las cuatro siguientes décadas, y por otro, la proyección internacional de Octavio Paz a partir de su descubrimiento de la India, país en donde representará a México como embajador hasta 1968.

Casualmente, ni Paz ni Cernuda viven en México cuando se publican sus respectivos libros en Joaquín Mortiz, por lo que la correspondencia se vuelve crucial. Mientras que no han aparecido hasta ahora cartas entre Cernuda y Díez-Canedo, sí consta por el epistolario del poeta español que éste aguardaba con impaciencia la publicación de su libro Desolación de la quimera, cuyo original había entregado al editor a mediados de 1961 y desconfiaba de que saliera en el plazo acordado (Valender: cartas 940, 960, 979, 999 y 1013). En cambio, Octavio Paz y Díez-Canedo tienen una comunicación directa en donde a pesar de las tensiones que suelen acompañar a todo proceso de edición, se mantiene un tono de cordialidad y entusiasmo.

Díez-Canedo escribe a Paz en mayo de 1962, preocupado porque no ha recibido el original de Salamandra. Éste no llega por correo como lo

3 Nota de James Valender en la carta 374 del Epistolario de Cernuda: "Cernuda había conocido a Octavio Paz en Valencia, en el verano de 1937...” (334).

${ }^{4}$ Bernabé Fernández Canivell (1907-1990). Poeta e impresor malagueño, amigo de los poetas de la Generación del 27. 
habían acordado, sino que el mismo Paz lo entrega a fines de junio, en un viaje a México.

La relación entre Joaquín Díez-Canedo y Octavio Paz no era reciente, como se dijo antes; iba más allá de una relación editor/autor (de por sí nunca trivial), pues de fondo estaba la impronta de la Guerra Civil española. Octavio Paz había asistido al Congreso de Intelectuales Antifascistas en Valencia en 1937, donde había estado también don Enrique Díez-Canedo (Díez-Canedo: Carta 90, 164-166); esto era algo que para Joaquín tenía un valor muy especial.

Además de concentrarse en la literatura mexicana contemporánea, a Díez-Canedo le interesaba poner al alcance del público a autores extranjeros del momento, mediante buenas traducciones, como fue el caso de Breton, finalmente traducido por Agustí Bartra.

Por otro lado, como a Paz, le interesaba la tradición francesa y la literatura francesa - “[de] actualidad", comenta con cierta sorpresa Octavio Paz cuando se entera de que una novela de Jean Cau, más conocido en Francia como periodista, será publicada en Mortiz-, que también había sido uno de los temas en que su padre Enrique había trabajado toda su vida y conocía a fondo como traductor.

Como documento aparte se incluye aquí la orden de producción de Salamandra (27 de julio de 1962), con lo que se puede tener una idea precisa de lo que tardó la edición del libro. Un dato curioso es que en las instrucciones al tipógrafo, se indica: "igual que Desolación de la quimera". Ambos títulos se empezaron a distribuir en diciembre de 1962.

Editar Salamandra llevó tan sólo cuatro meses. Un tiempo récord para un libro considerando las circunstancias y condiciones de producción de entonces. Contento con haber cumplido con el plazo previsto, en la carta del 28 de noviembre donde Díez-Canedo anuncia a Paz la salida de su libro, sólo se refiere a las "peripecias" ocurridas durante la edición: "Algún día podremos conversar de las muchas peripecias que ha tenido tu Salamandra..."

En Joaquín Mortiz, Octavio Paz publicó en primeras ediciones, además de Salamandra (1962): Cuadrivio (1965), Blanco (1967), Claude Lévi-Strauss o el nuevo festín de Esopo (1969), Ladera este (1969), Conjunciones y disyunciones (1969), El signo y el garabato (1973), Versiones y diversiones (1974), Renga (con Jacques Roubaud, Edoardo Sanguinetti y Charles Tomlinson) (1972) y El ogro filantrópico (1979). 


\section{CARTAS 1961-1962}

París, 30 de agosto de 1961.

Señor Joaquín Díez Canedo, Fondo de Cultura Económica, Avenida Universidad 975, México, D.F., México.

Querido Joaquín:

Un joven escritor francés, Jean Duvignaud, irá a México a mediados de septiembre o principios de octubre. Le he dado tu nombre y el de otros amigos (Orfila, Xirau, etc.), contando que ustedes podrían orientarlo y ayudarlo.

Duvignaud escribe en la Nouvelle Revue Française y en otras muchas revistas y periódicos de este país. ${ }^{5}$ Gracias de antemano por todo lo que hagas por él.

Cernuda me habló, vagamente, de ciertos proyectos editoriales. ${ }^{6}$ Carlos Fuentes, cuando pasó por aquí, me dio más detalles. Ya te imaginarás lo que me alegra pensar que al fin tendremos una editorial en la que la literatura tenga el lugar central que le corresponde. No sé cuáles sean tus proyectos. Por mi parte, espontáneamente, te ofrezco mi

5 Jean Duvignaud (1921-2007), sociólogo, antropólogo ensayista y novelista francés. Por estos años, en el FCE se publicó su libro Sociología del teatro (1966); posteriormente El sacrificio inútil (1979), El juego del juego (1982), Sociología del conocimiento (1982), y otros.

${ }^{6}$ Luis Cernuda y Octavio Paz se conocieron en Valencia en 1937 y posteriormente se mantuvieron en contacto por correspondencia, como puede verse por las múltiples referencias al poeta mexicano en el epistolario del sevillano. Las cartas de Cernuda a Paz se conocerán algún día. En el otro sentido, según un testimonio que recoge Valender, Cernuda, en 1963, decidió romper las cartas que conservaba, entre las cuales estarían las de Octavio Paz (Valender, "Nota a la edición”: LXI-LXII). 
colaboración; tengo algunas ideas sobre ciertos libros y colecciones; pero no me atrevo a decirte nada hasta no tener noticias tuyas.

Un abrazo,

Octavio Paz. 
México, D. F. 4 de diciembre de 1961.

Sr. Octavio Paz

Embajada de México

9, rue de Longchamp

París, Francia

\section{Querido Octavio:}

Apenas llegué y empecé a complicarme con las tareas de rutina y ya en este momento yazgo debajo de un montón de problemas sin solución $\mathrm{y}$ asuntos pendientes.

Así las cosas, no quiero dejar pasar más tiempo sin ponerte estas líneas, en primer lugar para agradecerte muy de veras los buenos ratos de París que os debo, tanto a Bona ${ }^{7}$ como a ti. Y en segundo lugar para puntualizar, por si ya se te hubieran olvidado, las cosas a que te comprometí en relación con mis futuras actividades inminentes. A saber:

1) La Salamandra. Me gustaría tener una idea lo más exacta posible, de cuántos poemas piensas incluir en el libro, de qué extensión, etc. Para ir haciendo ya mis cálculos de formato, tipo, serie y posible precio de venta, y prepararte un contrato.

2) La traducción de los poemas de A. O. Barnabooth. Prácticamente ya tengo contratado el libro, de modo que puedes empezar cuando gustes si, como supongo, tienes a mano el original. De lo contrario dímelo para que te lo envíe.

3) El tomo de Breton. Esto queda enteramente a tu gusto (puede andar entre las 200 y las 400 páginas), y supone, además del plan mismo de la edición, la obtención de la aquiescencia del autor y

${ }^{7}$ Bona [Tibertelli] de Mandiargues (1926-2000), pintora italiana. En 1958 hizo un viaje a México con el escritor surrealista André Pieyre de Mandiargues y exhibió su obra en la galería de Antonio Souza. Amigos de Octavio Paz, quien los introdujo al mundo intelectual y de la pintura mexicana. En París ella y Paz tuvieron una relación amorosa que no duraría mucho. 
las conversaciones preliminares para llegar con él a la firma del contrato correspondiente.

4) Una, dos, tres páginas con todas las listas y sugestiones de orden general con que quieras favorecerme.

5) Todo lo demás que se te ocurra.

Creo que esto resume con bastante aproximación lo que conversamos allá, por más que ahora empiece a parecerme algo remoto. Perdóname, por lo mismo, el aire de negocios que tiene toda esta carta, ya que se trata precisamente de eso, es decir, de una carta de negocios.

Te abraza

Joaquín Díez Canedo. 
París, a 18 de diciembre de 1961.

\section{[CARTA MANUSCRITA]}

Querido Joaquín:

Contesto a tus preguntas.

Salamandra: El libro está terminado. Se divide en tres secciones. En total, unas 110 páginas, a máquina, doble espacio. Se podría hacer un volumen parecido al primer Libertad bajo Palabra (unas 128 páginas). ${ }^{8}$

Breton: Aceptó, entusiasta. Pensamos en una "trilogía": Nadja, Los Vasos Comunicantes y El Loco Amor, con una introducción mía. Hablé después con Monique Lange: ${ }^{9}$ desde 1960, Fabril (Buenos Aires) tiene una opción sobre esos tres libros. Monique me prometió que inmediatamente escribiría a Fabril, ${ }^{10}$ sin decirle que otro editor se interesa, pidiéndole respuesta definitiva. Hay que esperar la respuesta de Buenos Aires. En caso de que los argentinos se decidan por la compra de esos libros, podríamos pensar en otro volumen, compuesto por los escritos teóricos (Manifiestos surrealistas, etc.). Pero, a mi juicio, hay que aguardar la respuesta de Fabril. Los derechos de los manifiestos, por otra parte, pertenecen a otro editor. Ya te informaré.

Larbaud: Yo no podría empezar la traducción antes de febrero. Creo que la terminaría en un tiempo relativamente corto. Sin embargo, no quisiera "entretenerte" demasiado. ¿Para cuándo necesitas esa traducción?

${ }^{8}$ Octavio Paz, Libertad bajo palabra, primera edición en la colección Tezontle del Fondo de Cultura Económica, 1949.

9 Monique Lange (París, 1926-1996). Secretaria del servicio de traducción de la editorial Gallimard. Trabajó en esta editorial con el escritor y activista de la resistencia Dyonis Mascolo. Compañera de Juan Goytisolo desde 1956, con quien se casó en 1978.

10 Se trata de la Compañía General Fabril Editora de Buenos Aires, derivada de una empresa dedicada a la producción de fósforos, textiles, papel e industria gráfica que empieza a editar libros a fines de la década de los ańos cincuenta. Son los primeros en traducir a Italo Calvino; traducen también a Milosz, Celine, Mircea Eliade, Ezra Pound, Umberto Eco, Roger Bastide, entre otros. Publican la $1^{\text {a }}$ edición de Sobre héroes y tumbas (1961), de Sabato, que después edita Sudamericana en versión definitiva [Agradezco esta información a Margarita Pierini, de la Universidad de Quilmes]. 
Te deseo éxito —en verdad lo deseo: por ti y por "ella" (la literatura). Y por nosotros tus amigos.

Saludos afectuosos para tu mujer. Y para ti.

Un abrazo de

Octavio Paz. 
París, a 15 de marzo de 1962.

Sr. Joaquín Díez-Canedo

Güaymas 33,

México 7, D. F.

Querido Joaquín:

Tu silencio me tenía alarmado. Celebro que se deba a exceso y no a falta de trabajo. Según te dije, tengo el libro listo. Lo voy a copiar cuidadosamente y te lo enviaré, por correo aéreo, en unos 8 o 15 días.

Veo que te inclinas por la actualidad literaria. No tengo la mejor opinión de Cau, como novelista (es un periodista excelente). ${ }^{11}$ Ojalá que publiques también los libros que cuentan realmente. Monique Lange me dice que la editorial Fabril sólo se interesa en "L'Amour Fou", de modo que tú podrías publicar "Nadja" y "Los Vasos Comunicantes". Podrías publicarlos en un solo volumen. ${ }^{12} \mathrm{~A}$ mí me encantaría hacer el prólogo.

Un abrazo afectuoso,

Octavio.

P. S. Tú me dirás cuándo empiezo a traducir los poemas de Barnabooth.

Perdona el tono de esta carta escrita a la carrera.

[POSDATA MANUSCRITA]

${ }^{11}$ Jean Cau (1925-1993). Escritor e intelectual de la posguerra, secretario de Jean Paul Sartre de 1947 a 1953. Periodista colaborador de France Observateur, L’Express, Les Temps Modernes, Le Figaro Littéraire, Paris Match. Autor de varias novelas. Por La pitié de Dieu, recibió el premio Goncourt en 1961. Traducida en Joaquín Mortiz por María Teresa Gallego y María Luisa Baeza con el título La compasión divina (Col. Novelistas contemporáneos, septiembre de 1962).

${ }^{12}$ Los libros de Breton se publicarán en volúmenes sueltos en la Serie del Volador, traducidos por Agusti Bartra: Nadja, segundo título de la serie, después Los vasos comunicantes y finalmente El amor loco. 
Mayo 221962.

Sr. Octavio Paz

Embajada de México

9, Rue de Longchamp

París, Francia

\section{Querido Octavio:}

La noticia de tu próximo cambio me alegra y me preocupa, por las consecuencias que puede tener para nuestros planes bretonesios y barnaboothianos. ${ }^{13}$ Pero como sé que vas a venir a México antes, confío en que tendremos ocasión de conversar largamente esto.

Lo malo es que hasta el momento no he recibido todavía el original de La Salamandra, cuyo envío me anunciabas como próximo en tu carta del día 15 de Marzo ¿qué pasa con él? Te ruego que me escribas cuanto antes porque estoy realmente preocupado.

Con mi enhorabuena más cordial recibe un afectuosos abrazo de

Joaquín Díez-Canedo.

$\mathrm{JDC} / \mathrm{mmb}$

13 Octavio Paz, ministro consejero de la embajada de México en París, dejó Francia a principios de julio de 1962 (Carta a Jaime Gil de Biedma en Valender: 1045). Ese mismo año es nombrado embajador en la India, cargo en el que estará "poco más de seis años" (Paz: 26). 
París, a 30 de mayo de 1962.

Sr. Joaquín Díez Canedo, Avándaro, S.A.

Güaymas 33, México 7, D. F.

Querido Joaquín:

Respondo brevemente a tu carta; estaré en México entre el 15 y el 20 de junio a más tardar. Llevaré conmigo Salamandra. Lo de Breton, si quieres publicar los manifiestos y otros textos, hay que comprárselos al editor Jean Louis Pauvert. ${ }^{14}$ Su dirección es: 8 rue de Nesles, París $6^{\text {eme }}$.

Yo no me puedo ocupar del asunto porque tengo mil problemas pendientes. Por supuesto, en el momento oportuno, me gustaría mucho escribir un texto sobre el libro de Breton. Ya hablaremos sobre lo de Larbaud.

Un abrazo.

Octavio Paz.

14 Sic por Jean-Jacques Pauvert, editor francés nacido en 1926, fundador de Éditions Pauvert en 1947, famosa por el escándalo que causó la publicación de las obras completas del marqués de Sade; incorporada al grupo Hachette de 1973 a 1979 y filial de Fayard desde 1999. 
Ashoka Hotel

New Delhi

Nota: RECIBIDO 25 OCT. 1962.

[CARTA MANUSCRITA]

A 17 de junio de $1962^{15}$

Querido Joaquín: Llegó el Presidente con su comitiva, y se fue; llegaron las lluvias y se han ido; todas la mañanas un cuervo llega a mi ventana, se va y regresa al otro día — sólo Salamandra ni llega, ni se va, ni regresa. ¿Qué pasa? ¿No es invulnerable al frío, al calor, y al veneno? Por aquí anduvo Agustín Yánez pero con la gente, los discursos, los banquetes, los textos políticos, los fotógrafos; los periodistas, los banqueros, los líderes, los militares, etc., se pasó el tiempo sin que pudiese preguntarle nada. ${ }^{16}$ Él, por supuesto, fue fiel a su vocación de monolito. Me imagino, sin embargo, que la editorial ya recibió el bautismo de fuego. Desde aquí celebro tus victorias y combates. Escríbeme unas líneas y dame noticias de mi libro.

Aquí no pasa nada - excepto pájaros maravillosos, y, de vez en cuando, algunas mujeres menos maravillosas. El clima es perfecto —aunque parezca mentira.

Saluda a tu mujer con afecto. Y para ti un abrazo cordial de tu amigo,

Octavio.

${ }^{15}$ Hay un error en la fecha, la carta debe ser del mes de octubre. La visita de Estado del presidente López Mateos a la India abarcó del 4 al 10 de octubre de 1962. Existe una crónica de este viaje escrita por Agustín Yáñez (33-75).

${ }^{16}$ Agustín Yáñez, Subsecretario de la Presidencia, viajó con la comitiva de Adolfo López Mateos a la India. 


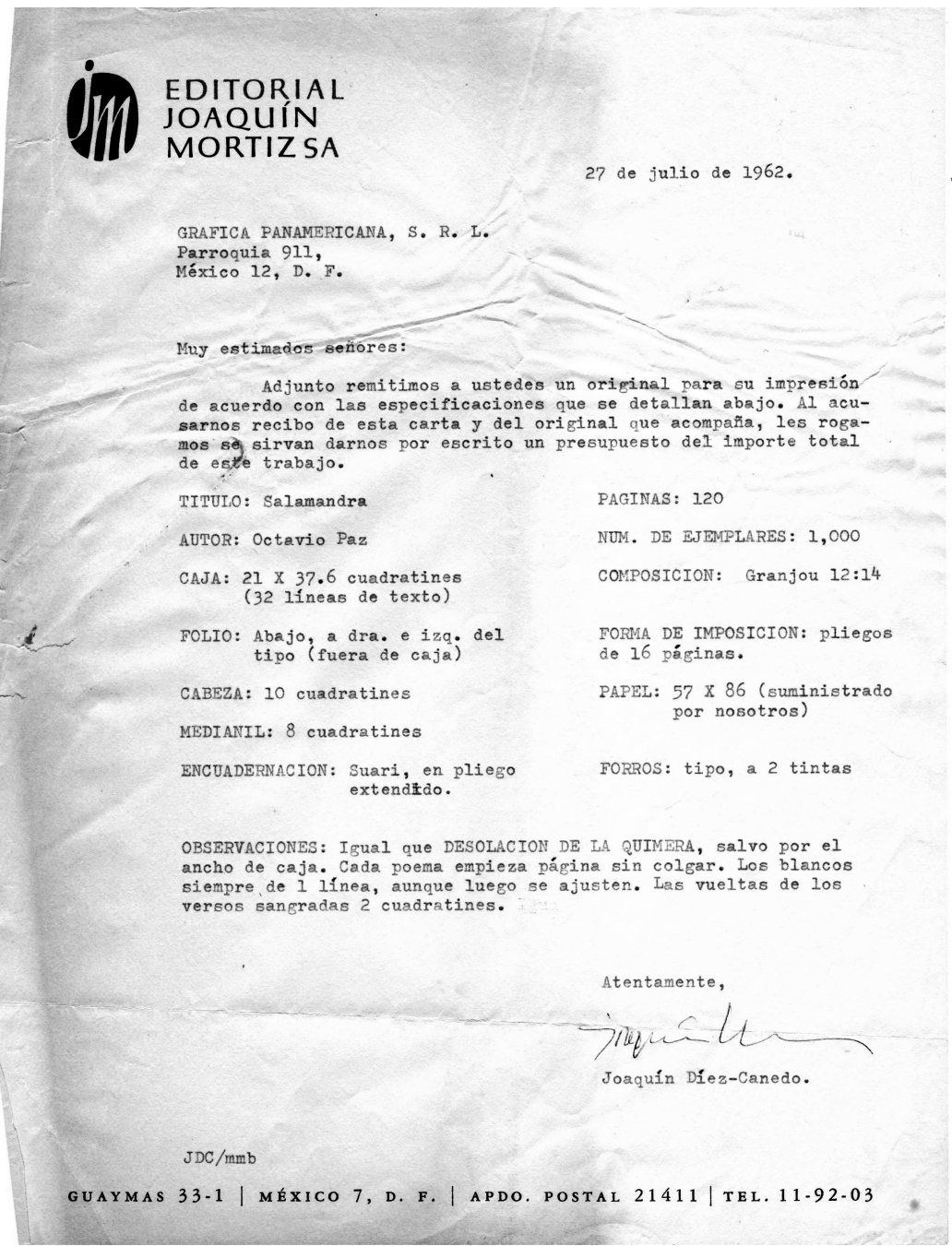

Orden de Producción de Salamandra, 27 de julio de 1962 
14 de noviembre de 1962.

Sr. Octavio Paz

Ashoka Hotel

New Delhi.

Querido Octavio:

Recibí tu carta fechada el 17 de junio de 1962, confusión que te envidio y aprovecho para disculpar mis propios e involuntarios retrasos.

Tu libro está impreso desde la semana pasada, espero tener ejemplares a fines de ésta o en la próxima; en cuanto salga te enviaré algunos por correo aéreo.

Agustín Yáñez viene a verme 2 ó 3 veces por semana, pero hasta ahora no he podido sacarle nada en limpio del viaje, de sus impresiones personales ni de la que le causó su encuentro contigo en esas tierras también flacas. Su novela salió hace ya un par de semanas, junto con la de Cau y la de Rosario Castellanos, y ha tenido espléndida acogida y muy buena venta. ${ }^{17}$

Te abraza,

Joaquín Díez Canedo.

$\mathrm{JDC} / \mathrm{mmb}$

${ }^{17}$ Los tres primeros títulos de la colección Novelistas Contemporáneos de Joaquín Mortiz publicados en septiembre-octubre de 1962 fueron: Las tierras flacas de Agustín Yáñez, La compasión divina de Jean Cau y Oficio de tinieblas de Rosario Castellanos. 
México, D. F., 28 de noviembre de 1962.

Sr. Octavio Paz

Ashoka Hotel

New Delhi.

Querido Octavio:

Al fin salió ya Salamandra y hoy mismo te hago enviar por correo aéreo dos ejemplares y espero noticias tuyas para ver a quiénes debo enviar en tu nombre los demás que te corresponden: teóricamente hasta 20, a los que puedes agregar una lista complementaria de mi servicio de prensa, que serán unos 60 nombres en su mayoría nacionales.

Algún día podremos conversar de las muchas peripecias que ha tenido tu Salamandra en su camino de Güaymas a Güaymas pasando por los talleres de impresión, barnizado y encuadernación, etc.- No estoy muy seguro de que el libro te guste, pero espero que sí. Pienso ponerlo en circulación a partir del lunes próximo, día 3 de diciembre, junto con el de Luis Cernuda.

Los comentarios y el ritmo de las ventas de las 3 novelas que saqué antes, hace exactamente un mes, siguen siendo de lo más entusiasta y alentador. Ya tengo un buen arreglo con Colombia y estoy por llegar a otro espléndido en Chile (no tanto por desgracia para los libros de poesía como para la serie de novela). Parece que de Argentina también podremos conseguir algo, aunque la situación actual del país no deja mucho campo al optimismo. En Espańa la impresión de los Seix Barral es también satisfactoria; pero hasta ahora sólo el libro de Yánez ha pasado la censura y ellos quieren hacer un lanzamiento un tanto espectacular, cuando menos con una media docena de libros simultáneamente.

Te abraza

Joaquín Díez-Canedo.

$\mathrm{JDC} / \mathrm{mmb}$ 
Embajada de México. Nueva Delhi, India

Nueva Delhi, a 12 de diciembre de 1962

Recibido 19 dic. 1962

Señor Joaquín Diez-Canedo,

Guaymas 33-1

México 7, D. F.

Querido Joaquín:

Hoy recibí los dos ejemplares de Salamandra. No sé por qué dudabas: al contrario, la edición me parece muy bonita. El tipo, la disposición, el tamaño, los colores y la portada. Te confieso que temía algo demasiado "moderno"; por fortuna, tu buen gusto es más poderoso que las modas un tanto chillonas de las nuevas editoriales. Te agradezco de verdad el libro. Mándame, por favor, las tres novelas y el de Cernuda (es compra, no regalo).

Lo de la distribución me inquieta (no por mí, que no soy best-seller, sino por nuestra literatura). Creo que ya es hora de que el Gobierno tome cartas en el asunto. Quizá debería subvencionarse a los editores mexicanos que venden libros en el extranjero, para que nuestros precios no resulten demasiado altos y podamos competir con argentinos y españoles. También, aunque ese es problema distinto, habría que ver la manera de concertar acuerdos para que se pueda retirar el producto de las ventas, cuando se trate de países con control de cambios. Escríbeme y dime qué se puede hacer. Yo, apenas reciba tus orientaciones, podría escribir a Moreno Sánchez y al mismo Presidente. Creo que no sería desoído del todo. Tengo la impresión de que el régimen desea hacer algo en este campo.

Mis ejemplares: te envío sólo una lista para el extranjero. ${ }^{18}$ Son 58 pero pueden eliminarse los que llevan un asterisco. Los de México, como tenemos comunes, bastará con tu lista. No olvides enviarle por aéreo un ejemplar a Edith Aron, 17 rue Marthe-Edouard, Meudon (Seine et Oise), France, y otro a Giuseppe Bellini, vía F.LLI, Bronzetti, Milano, Italia. La primera es la traductora de una antología mía, en alemán: el segundo, al italiano. Ambos necesitan con urgencia Salamandra, para completar su selección. Los dos libros deben salir el año próximo.

${ }^{18}$ Adjunta, una larga lista que no se incluye aquí. 
Estoy muy satisfecho con nuestra Salamandra. Descubrí algunas erratas, pero es milagroso que no fuesen más. Corregí las pruebas e, inclusive, el manuscrito, en un estado de espíritu poco propicio. Aquí, en cambio, la calma más perfecta, lindante con un aburrimiento infinito como los dioses de la India, me rodea. Sin embargo, apenas escribo. Pero pienso volver a mi manía. En estos meses quiero terminar el pequeño ensayo (unas 120 páginas) sobre amor y erotismo. Ojalá tuviese sitio en alguna de tus colecciones. También corregiré y completaré el segundo tomo de Las Peras del Olmo (ensayos y artículos sueltos) que tal vez publicará Barral. Y tengo otros proyectos.

¿Has visto a Gorostiza? Sería espléndido que lograses arrancarle la novela. ${ }^{19}$ Entre nosotros (es confidencial) está terminada hace años y sólo le falta un prólogo, unas cuatro o cinco páginas. Los escrúpulos de ese hombre son increíbles, admirables y exasperantes. Lo que me cuentas de la censura española me da mala espina. Por fortuna, mi libro les resultará ininteligible y pasará la prueba.

Salúdame con afecto a los amigos. Un recuerdo cariñoso para tu mujer.

Un abrazo, Octavio Paz.

¡Felices Pascuas! [MAnUscrito]

19 Christopher Domínguez Michael señala, respecto a José Gorostiza, que "tras Muerte sin fin, quedan algún poema, varios proyectos y una novela que, según contaba Octavio Paz, el poeta destruyó al compararla desfavorablemente con Le bain de Diane (1956), de Pierre Klossowski” (202). 
11 de enero de 1963.

Sr. D. Octavio Paz

Ashoka Hotel

New Delhi.

Querido Octavio:

Recibí tu carta del 19 de diciembre y ya hice enviar todos los ejemplares de la lista que me mandaste. Lamento esas erratas de Salamandra aunque por lo que me dices pienso que no son demasiado graves.

Por supuesto que cuento con tu ensayo sobre amor y erotismo, y si no tuviese sitio en ninguna de mis colecciones haríamos una colección especial. Pero no te asustes: supongo que irá muy bien en la serie pequeña que estoy planeando dentro del aspecto y características de la Biblioteca Breve, donde entraría también probablemente lo de Gorostiza. Hablé con él el otro día y me prometió hacer un esfuerzo por desprenderse de su original y entregármelo.

No te preocupes mucho por lo de la distribución, porque creo que todo anda bien y que andará cada vez mejor. En realidad los problemas en el exterior no son de los que no pueden resolverse con el tiempo, no comparto esa idea de la subvención a los editores, porque siempre he pensado que en cualquier terreno subvencionar es un poco echar a perder; o en otras palabras, que es mejor que la libre empresa se las arregle sola. Ojalá pueda seguir pensando lo mismo de aquí a 3 ańos.

Te mando las novelas, el libro de Cernuda y lo que vaya saliendo, junto con los mejores votos para el año que empieza y un fuerte abrazo.

Joaquín Díez-Canedo. 
Embajada de México

Delhi, a 28 de junio de 1963.

[CARTA MANUSCRITA]

Querido Joaquín:

Mil veces he querido escribirte y otras tantas algo se ha interpuesto: un visitante, el teléfono, el calor (el calor, el calor, el calor). Gracias, aunque tardías, por el envío de las novelas y del Cernuda, también tardío (tarde, tarde, tarde). En cambio, ¿nunca recibiré los ocho ejemplares prometidos de Salamandra? ¿Nunca, nunca, nunca? No es posible. Recuerda que sólo recibí dos. Es inicuo.

¿Cómo van tus trabajos editoriales? ¿qué recepción han tenido tus libros? Entre las cartas que he recibido con motivo de Salamandra, hay una, de París, que contiene una frase que te gustaría: "la edición, la tipografía, es impecable". No sé si sea verdad pero alegra leer cosas así.

Yo he escrito apenas nada, sin embargo, tengo varios proyectos y alguno de ellos se realizará. Ya te escribiré con noticias. Guarda para mí un pequeño lugar en tus proyectos editoriales.... He viajado mucho, he visto muchas tumbas de grandes de este mundo y muchas ruinas y cementerios de civilizaciones. Ahora debo detenerme y poner en claro tantas impresiones. Ah! Te recomiendo a Homero Aridjis. ${ }^{20}$ Presiento que tiene verdadero talento. Y a Juan García Ponce... ${ }^{21}$

Saludos a tu mujer y para ti un abrazo,

Octavio.

${ }^{20}$ Homero Aridjis publicará en Las dos Orillas Mirándola dormir, cuarto título de la colección, y libro ganador del premio Villaurrutia en 1964.

${ }^{21}$ Juan García Ponce. Figura de paja, Joaquín Mortiz, 1964 (Serie del Volador). 


\section{BiBLIOGRAFÍA}

Cau, Jean. La compasión divina. Traducción María Teresa Gallego y María Luz Baeza. México: Joaquín Mortiz, 1962 (col. Novelistas contemporáneos).

Díez-Canedo, Aurora (edición y est. introd.). Enrique Diez-Canedo / Alfonso Reyes. Correspondencia 1915-1943. México: Fondo Editorial de Nuevo León / Universidad Nacional Autónoma de México, Instituto de Investigaciones Filológicas, 2012.

Domínguez Michael, Christopher. Diccionario crítico de la literatura mexicana (1955-2005). México: Fondo de Cultura Económica, 2007.

Fondo de Cultura Económica. Catálogo histórico, 2009.

Joaquín Mortiz. Catálogo 1981.

Kirkup, James. Obituary: Jean Cau <www.independent.co.uk>.

Pauvert, Jean Jacques. La travesía del libro. Memorias de Jean-Jacques Pauvert. Trad. de María José Furió Sancho. Madrid: Trama, 2011.

Paz, Octavio. Vislumbres de la India. Un diálogo con la condición humana. Barcelona: Seix Barral, 1995 (col. Biblioteca Breve).

Valender James (ed.). Luis Cernuda. Epistolario 1924-1963. Madrid: Residencia de Estudiantes, 2003.

Ulacia, Paloma y James Valender. "Rte. Joaquín Mortiz (entrevista a Joaquín Díez-Canedo)”, en vv.AA. Rte. Joaquín Mortiz. Edición homenaje. Guadalajara: Universidad de Guadalajara, 1994.

vv.AA. André Pieyre de Mandiargues. Pages mexicaines. París: Gallimard, 2009, ils.

Yáñez, Agustín. Proyección universal de México. Crónica del viaje realizado por el presidente de México Lic. Adolfo López Mateos a India, Japón, Indonesia y Filipinas, el año de 1962. [s.p.i., edición del autor], 1963.

\section{PÁginas Web}

$<$ www.sre.gob.mx>. 